\title{
LA ASISTENCIA RELIGIOSA EN EL ORDENAMIENTO CONSTITUCIONAL PERUANO
}

\author{
[Religious assistance in the peruvian constitutional framework]
}

\author{
ÓSCAR DÍAZ MUÑOZ ${ }^{1}$
}

\begin{abstract}
Resumen
Este artículo describe la situación de la asistencia religiosa en el Perú a partir de un estudio de su Constitución, la Ley de Libertad religiosa y la jurisprudencia del Tribunal Constitucional. El trabajo explica que el Estado peruano se caracteriza por un modelo de laicidad y colaboración con las entidades religiosas que garantiza la asistencia religiosa para los creyentes de todas ellas, conforme al principio de igualdad. A partir de lo anterior el trabajo concluye que en el Perú coexisten dos modelos asistencia religiosa y, desde esta perspectiva, revisa su aplicación en el ámbito de las Fuerzas Armadas y Policiales, los establecimientos penitenciarios y centros hospitalarios públicos.
\end{abstract}

Palabras clave: Asistencia religiosa, Laicidad, Estado y religión, Libertad religiosa, Perú.

\begin{abstract}
This article describes the situation of pastoral care in Peru based on a study of its Constitution, the Religious Freedom Act, and Constitutional Court decisions. This paper explains that the Peruvian State is characterized by a model of secularity and cooperation with religious entities, that guarantees pastoral care for their believers, under the principle of equality before the law. Based on the foregoing, the study concludes that two pastoral care models coexist in Peru and, from this perspective, reviews its application in the field of the armed forces and police, prisons, and public hospitals.

Key words: Pastoral care, Secularity, Law and Religion, Religious Freedom, Peru.
\end{abstract}

DOI: 10.7764/RLDR.10.121

\footnotetext{
${ }^{1}$ Doctor y Máster en Derecho por la Universidad de Zaragoza (España). Abogado por la Pontificia Universidad Católica del Perú. Asesor Jurisdiccional y ex Secretario Relator del Tribunal Constitucional del Perú. Miembro de la Asociación Peruana de Derecho Constitucional, del Consorcio Latinoamericano de Libertad Religiosa y del International Consortium for Law and Religion Studies (ICLARS). odiazmunoz@gmail.com
} 


\section{INTRODUCCIÓN}

Los instrumentos internacionales sobre derechos humanos, al tiempo de reconocer el derecho de libertad religiosa, señalan también sus formas de manifestación (individuales o colectivas), entre las que se cuentan la práctica, el culto, la celebración de ritos y la observancia ${ }^{2}$.

La asistencia religiosa es una de esas manifestaciones de este derecho fundamental, relativa a la práctica de la religión. Así lo ha entendido el Tribunal Constitucional del Perú:

Es innegable que el reconocimiento constitucional del derecho fundamental de las personas a profesar una determinada religión da lugar también al derecho a practicar los actos de culto y a recibir la asistencia religiosa correspondiente sin que se atente contra el orden público o contra la moral pública. Y es que la libertad religiosa no sólo se expresa en el derecho a creer, sino también en el derecho a practicarla ${ }^{3}$.

Por ello, Mantecón Sancho escribe que «aunque el derecho a recibir asistencia religiosa de la propia confesión no aparezca expresamente recogido en las Convenciones o Declaraciones internacionales sobre derechos humanos, va de suyo que la asistencia religiosa es una explicitación del derecho a practicar la propia religión» ${ }^{4}$.

Podemos definir la asistencia religiosa como «la acción del Estado para establecer la infraestructura y las condiciones adecuadas para que puedan recibir asistencia espiritual

\footnotetext{
${ }^{2}$ Cfr. Declaración Universal de Derechos Humanos (artículo 18) y Pacto Internacional de Derechos Civiles y Políticos (artículo 18.1).

${ }^{3}$ Sentencia del Tribunal Constitucional del Perú (STC) 2700-2006-PHC/TC, fundamento 13 (las cursivas son del original), cfr. también STC 6111-2009-PA/TC, fundamento 17.

${ }^{4}$ MANTECÓN SANCHO, Joaquín. "Asistencia religiosa de las confesiones minoritarias en las Fuerzas Armadas». Revista General de Derecho Canónico y Derecho Eclesiástico del Estado. N. 35 (2014) p. 1
} 
directa de sus respectivas confesiones los ciudadanos que tienen disminuidas las posibilidades de recibirla por encontrarse internados en centros caracterizados por un régimen de especial sujeción» ${ }^{5}$.

Esas situaciones de «especial sujeción» se presentan básicamente -y de ellas nos ocuparemos aquí- en el ámbito de los centros penitenciarios, las Fuerzas Armadas y Policiales y el sistema hospitalario estatal, aunque se podrían añadir otros centros asistenciales públicos, como las residencias para personas de la tercera edad o los orfanatos.

\section{MARCO CONSTITUCIONAL Y LEGAL}

La Constitución Política del Perú reconoce el derecho fundamental de libertad religiosa en su artículo 2, inciso 3, en los siguientes términos:

Toda persona tiene derecho:

$[\ldots]$

A la libertad de conciencia y de religión, en forma individual o asociada. No hay persecución por razón de ideas o creencias. No hay delito de opinión. El ejercicio público de todas las confesiones es libre, siempre que no ofenda la moral ni altere el orden público.

Como ya hemos apuntado, la asistencia religiosa viene a ser una manifestación de este derecho, pero que, por su propia definición, requiere de la cooperación del Estado.

Por ello, puede afirmarse que la asistencia religiosa encuentra su fundamento en el artículo 50 de la Constitución, que señala:

${ }^{5}$ LÓPEZ ALARCÓN, Mariano. «Asistencia religiosa». En: Derecho eclesiástico del Estado español. Javier Ferrer Ortiz (coord.). Pamplona: EUNSA, 1996, p. 305. 
Dentro de un régimen de independencia y autonomía, el Estado reconoce a la Iglesia Católica como elemento importante en la formación histórica, cultural y moral del Perú, y le presta su colaboración. El Estado respeta otras confesiones y puede establecer formas de colaboración con ellas.

Conforme a este precepto, si bien ninguna confesión tiene carácter estatal (principio de laicidad ${ }^{6}$ ), la Constitución «considera importante el componente religioso perceptible en la sociedad peruana y dispone que el Estado preste su colaboración a la Iglesia Católica y que pueda establecer formas de colaboración con las demás confesiones» ${ }^{7}$. Es en el marco de esta colaboración que encuentra cabida la asistencia religiosa, tanto para los fieles católicos como para los de otras confesiones, en aplicación del derecho-principio de igualdad religiosa (artículo 2, inciso 2, de la Constitución) ${ }^{8}$.

El Tribunal Constitucional ha sido enfático en el reconocimiento de la asistencia religiosa. Así, el supremo intérprete de la Constitución ha dicho que es parte del contenido de la libertad religiosa «recibir la asistencia o consejería religiosa, necesarias para la tranquilidad espiritual de las personas que pudieran encontrarse dentro de un régimen especial de sujeción, como por ejemplo en hospitales, asilos, centros de rehabilitación, centros de formación militar, establecimientos penitenciarios, entre otros. Ello es así en la medida que existe íntima relación de la libertad religiosa con el principio-derecho de dignidad de la persona humana (artículo 1 de la Constitución), por lo que es un derecho que el Estado debe proteger, si bien dentro de los límites previstos en nuestra Constitución»⿳9.

Naturalmente, la Ley 29.635, Ley de Libertad Religiosa (LLR), se ocupa del tema sub examine, señalando que toda persona tiene, entre otros, el siguiente derecho (artículo 3.c):

\footnotetext{
${ }^{6}$ Cfr. STC 3372-2011-PA/TC, fundamento 13; STC 6111-2009-PA/TC, fundamento 31.

${ }^{7}$ STC 6111-2009-PA/TC, fundamento 29.

${ }^{8}$ Cfr. STC 6111-2009-PA/TC, fundamentos 19 a 22.

${ }^{9}$ STC 2700-2006-PHC/TC, fundamento 14.
} 
Recibir asistencia religiosa por su confesión. Las instituciones públicas competentes adoptan las medidas y normas necesarias para facilitar la asistencia religiosa en el ámbito de las Fuerzas Armadas y de la Policía Nacional del Perú, en las prisiones, en los centros públicos hospitalarios, asistenciales y otros bajo su dependencia.

Por su parte, el Reglamento de la LLR (Decreto Supremo 006-2016-JUS) desarrolla el citado precepto legal del modo siguiente (artículo 6):

La asistencia religiosa en las instituciones públicas indicadas en el artículo 3 de la Ley se dispensa por los ministros de culto o agentes pastorales designados por las entidades religiosas ${ }^{10}$.

Los ministros de culto o agentes pastorales se identifican con la credencial emitida por la autoridad de la entidad religiosa a la que pertenecen, la misma que es renovada anualmente para efecto de facilitar la asistencia religiosa a la que se refiere la Ley.

Las Fuerzas Armadas y la Policía Nacional del Perú pueden establecer mecanismos administrativos que les permitan contar con ministros de culto o agentes pastorales de las entidades religiosas, los que, debidamente identificados, brinden asistencia religiosa a sus miembros.

Junto con estas normas, debemos tener presente que, en desarrollo del principio de colaboración del ya citado artículo 50 de la Constitución, la LLR regula los convenios de colaboración entre el Estado y las confesiones religiosas en los siguientes términos (artículo 15):

${ }^{10}$ Conforme al artículo 6.c de la LLR, «la condición de ministro de culto se acredita con documento auténtico expedido por la autoridad competente de la entidad religiosa». 
El Estado peruano, en el ámbito nacional, dentro de sus competencias, amparado en el artículo 50 de la Constitución Política del Perú, puede suscribir convenios de colaboración sobre temas de interés común, de carácter legal, con aquellas entidades religiosas que, estando inscritas en el registro a que se refieren los artículos precedentes, hayan adquirido notorio arraigo con dimensión nacional y ofrezcan garantías de estabilidad y permanencia por su número de miembros y actividades.

Los convenios, para ser aprobados como norma legal, deben tener el informe favorable del Ministerio de Justicia y del Ministerio de Economía y Finanzas.

Un convenio de colaboración es el Acuerdo entre la Santa Sede y la República del Perú de 1980. En este tratado internacional, como veremos seguidamente, se regula con detalle la asistencia religiosa a los fieles católicos en las Fuerzas Armadas y Policiales (artículos XI a XVII), en los centros hospitalarios estatales e instituciones penitenciarias (artículo XVIII).

Visto lo anterior, y siguiendo la tipología de modelos de asistencia religiosa que hace López Alarcón, podemos afirmar que en el ordenamiento jurídico peruano coexisten un modelo de concertación y uno de libre acceso. Dentro del primero, está el Acuerdo con la Iglesia católica de 1980 y los demás acuerdos que el Estado pueda suscribir con otras confesiones religiosas. En el segundo modelo entrarían aquellas confesiones que no cuenten con convenios de colaboración con el Estado, lo que no impide que sus fieles tengan derecho a la asistencia religiosa ${ }^{11}$.

\footnotetext{
${ }^{11}$ Según este autor, en el modelo de concertación «prevalece la fórmula del convenio entre la institución civil correspondiente y la confesión religiosa acerca de la aportación de recursos humanos y materiales por una y otra parte [...]». En el modelo de libre acceso de ministros religiosos al interior del centro para prestar asistencia espiritual, se establecen las condiciones que aseguren el buen orden y régimen interior, bien mediante convenio, bien unilateralmente. Las relaciones del centro con los ministros religiosos se reducirán a la autorización para el libre acceso con prestación de servicios de benevolencia o mediante contrato retribuido de naturaleza administrativa, civil o laboral (LÓPEZ ALARCÓN, Mariano. «Asistencia religiosa» ..., cit., p. 309).
} 


\section{ASISTENCIA RELIGIOSA EN LAS FUERZAS ARMADAS Y LA POLICÍA NACIONAL}

El Acuerdo entre la Santa Sede y la República del Perú de 1980 se ocupa de la asistencia religiosa católica en las Fuerzas Armadas y la Policía Nacional, en sus artículos XI a $\mathrm{XVII}$.

El artículo XI justifica este acuerdo por tratarse de la confesión religiosa mayoritaria en la sociedad peruana y señala que la asistencia religiosa se presta a través del Vicariato Castrense:

Consideradas las creencias religiosas de la mayoría nacional, el Estado continúa garantizando que se preste por parte del Vicariato Castrense la asistencia religiosa a los miembros de la Fuerza Armada, Fuerzas Policiales y a los servidores civiles de aquéllos que sean católicos ${ }^{12}$.

Coherente con la laicidad del Estado establecida en el Perú desde la Constitución de 1979, dicho Acuerdo señala que «ni el Vicario Castrense, ni los Capellanes dependientes de él, tendrán asimilación a grado militar ni a la Jerarquía Policial» (artículo XIII), aunque «los Capellanes Castrenses tendrán derecho a promociones similares al que tienen los empleados civiles de los Institutos Armados o Policiales» (artículo XIV). Como escribe Carpio Sardón, «desde la vigencia del Acuerdo con la Santa Sede, la asistencia religiosa católica no se constituye como un servicio público que haya sido integrado en la organización militar ni el personal es asimilado a las Fuerzas Armadas ni a sus grados. Se considera, más bien, que es

\footnotetext{
12 Este Acuerdo, aunque suscrito en 1980, mantiene actualidad en cuanto a «las creencias religiosas de la mayoría nacional». En los Censos Nacionales 2017 (últimos realizados), a la pregunta sobre qué religión profesa el encuestado, un 94,91\% dijo tener una religión, siendo mayoritaria la Católica (76,03\%), seguida de la Evangélica (14,07\%), otras 4,81\% y ninguna 5,09\% (cfr. Instituto Nacional de Estadística e Informática CPV2017. Disponible en: http://censos2017.inei.gob.pe/redatam/).
} 
un servicio de asistencia religiosa a los fieles católicos, por parte de la Iglesia católica, la que debe ejercer su atención dentro del derecho constitucional de libertad religiosa» ${ }^{13}$.

Por las peculiares circunstancias en que deberá ejercer su servicio, el Vicario Castrense debe ser peruano de nacimiento y, teniendo en cuenta su condición episcopal, será nombrado por la Santa Sede, de acuerdo con el presidente de la República (artículo XV).

Los Capellanes Castrenses serán nombrados por el Vicario Castrense y reconocidos por los Comandos Generales de los Institutos Armados y Direcciones Superiores de los Institutos Policiales (artículo XVI). En lo posible, serán tomados del Clero de la Diócesis en cuyo territorio se encuentra la Unidad Militar en la que prestarán servicios (artículo XVII).

En el caso de las confesiones que no han firmado acuerdos de colaboración con el Estado se aplica el régimen general de la LLR y su Reglamento. Es decir, las Fuerzas Armadas y Policiales deben adoptar las medidas y normas necesarias para facilitar la asistencia religiosa (artículo 3.c LLR) que se dispensará por los ministros de culto o agentes pastorales designados por las entidades religiosas, debidamente identificados con la credencial emitida por la autoridad de la confesión a la que pertenecen, la cual debe ser renovada anualmente (artículo 6 del Reglamento LLR).

\section{ASISTENCIA RELIGIOSA EN ESTABLECIMIENTOS PENITENCIARIOS}

El Tribunal Constitucional ha tenido la oportunidad de pronunciarse sobre la asistencia religiosa penitenciaria del modo siguiente:

\footnotetext{
${ }^{13}$ CARPIO SARDÓN, Luis Andrés. «La asistencia religiosa». En: Libertad religiosa y aconfesionalidad del Estado peruano. Francisco Bobadilla Rodríguez, Jéssica Chirinos-Pacheco y Javier Ferrer Ortiz (coordinadores). Lima: Yachay Legal, 2020, p. 210.
} 
[...] atendiendo a que la Constitución establece como derecho fundamental de todas las personas -incluidos los reclusos- a la libertad religiosa -la misma que se asienta en el principio-derecho de dignidad de la persona humana- y que el principio del régimen penitenciario tiene por objeto reeducar, rehabilitar y reincorporar al penado a la sociedad, recibir asistencia religiosa como un medio penitenciario y como un fin en sí mismo de resocialización a través de la fe, no constituye una violación constitucional a los valores del orden público y a la seguridad ciudadana.

Dicho esto, es evidente que la persona que se encuentra internada procesada o sentenciada- en un establecimiento penitenciario no puede ser impedida, prima facie, de ejercer su derecho fundamental a la libertad religiosa; siempre que de ello no deriven afectaciones a los derechos fundamentales de los demás o no impliquen actos de intolerancia que pongan en riesgo otros bienes constitucionales como el orden público, la moral, la seguridad de la población, bienes que, según el artículo 44 de la Constitución le corresponde también proteger al Estado ${ }^{14}$.

En el estudio de la asistencia religiosa en instituciones penitenciarias, hay que tener presentes las Reglas Mínimas de las Naciones Unidas para el Tratamiento de los Reclusos (Reglas Nelson Mandela), aprobadas en la Asamblea General del 17 de diciembre de $2015^{15}$. La Regla 65 se ocupa de nuestro objeto de estudio:

1. Si en el establecimiento penitenciario hay un número suficiente de reclusos de una misma religión, se nombrará o aprobará un representante calificado de ese culto. Cuando el número de reclusos lo justifique y las circunstancias lo permitan, dicho representante prestará servicios a tiempo completo.

\footnotetext{
${ }^{14}$ STC 2700-2006-PHC/TC, fundamentos 15 y 16.

15 Disponible en: https://www.unodc.org/documents/justice-and-prison-reform/Nelson_Mandela_Rules-Sebook.pdf [consulta 2-10-2020].
} 
2. El representante calificado que haya sido nombrado o aprobado conforme al párrafo 1 de esta regla estará autorizado a organizar periódicamente servicios religiosos y a efectuar, cada vez que corresponda, visitas pastorales en privado a los reclusos de su religión.

3. Nunca se negará a un recluso el derecho de comunicarse con el representante autorizado de una religión; y, a la inversa, cuando un recluso se oponga a ser visitado por el representante de una religión, se deberá respetar plenamente su actitud.

También vinculada con la asistencia religiosa, aunque más amplia, es la Regla 66 del mismo cuerpo normativo, que dispone: «En la medida de lo posible, se autorizará a todo recluso a cumplir los preceptos de su religión, permitiéndosele participar en los servicios organizados en el establecimiento penitenciario y tener en su poder libros de observancia e instrucción religiosas de su confesión».

Según ya hemos visto, la LLR contempla la asistencia religiosa en las prisiones (artículo 3.c). El artículo 6 de su Reglamento indica que esta se imparte por los ministros de culto o agentes pastorales designados por las entidades religiosas, que se identifican con la credencial emitida por la entidad religiosa a la que pertenecen, la cual debe renovarse anualmente.

En el Código de Ejecución Penal (Decreto Legislativo 654) encontramos un capítulo denominado «Asistencia religiosa» (capítulo VIII del Título III), con las siguientes disposiciones:

Artículo 93.- La Administración Penitenciaria garantiza la libertad de culto y facilita los medios para ejercitarla. El interno puede solicitar ser asistido por ministros de la religión que profesa. 
Artículo 94.- Ningún interno será obligado a asistir a los actos de culto ni impedido de asistir a los mismos.

En desarrollo de tales artículos, el Reglamento del Código de Ejecución Penal (Decreto Supremo 015-2003-JUS), dentro de los derechos de los internos en centros penitenciarios, reconoce el derecho de formar agrupaciones religiosas (artículo 11.14), mientras que el artículo 16.8 recuerda el deber de los internos de respetar los principios religiosos de los demás ${ }^{16}$.

Según dicho Reglamento, el interno podrá ser asistido por un ministro o representante de su religión y las actividades religiosas podrán ser promovidas por las confesiones e Iglesias a través de ministros, sacerdotes, representantes o agentes pastorales (artículo 148).

Los miembros de las organizaciones religiosas e Iglesias deberán acreditar su representación para los efectos del otorgamiento del permiso, antes del inicio de su labor. Las actividades de culto, promoción y asistencia a los internos serán informadas a la dirección del establecimiento penitenciario a través del servicio social (artículo 149). Los grupos religiosos que obtengan permiso de ingreso al establecimiento penitenciario se sujetarán a las reglas de seguridad y normas internas del mismo (artículo 151).

Finalmente, debemos destacar que el artículo 150 de este Reglamento señala que la Administración penitenciaria facilitará el o los ambientes necesarios para el ejercicio del culto y demás actividades pastorales.

\footnotetext{
${ }^{16}$ Cfr. ARREBOLA FERNÁNDEZ, Ángel. «La asistencia religiosa penitenciaria. Comentario a la Sentencia 27002006-PHC/TC». En: El derecho fundamental de libertad religiosa: jurisprudencia y doctrina constitucional. Óscar Díaz Muñoz, Gerardo Eto Cruz y Javier Ferrer Ortiz (coordinadores). Lima: Tribunal Constitucional - Centro de Estudios Constitucionales, 2014, p. 282.
} 
En el caso de reclusos católicos, el Acuerdo entre la Santa Sede y la República del Perú establece que el Estado garantiza que se preste asistencia religiosa a los católicos internados en establecimientos penitenciarios. Para ello, los Capellanes requieren contar con nombramiento eclesiástico, que será presentado a la autoridad competente (artículo XVIII).

La colaboración entre el Estado y las confesiones en el ámbito de la asistencia religiosa penitenciaria se ve facilitada con la suscripción de «Convenios marco de cooperación interinstitucional» entre estas y el Instituto Nacional Penitenciario (INPE) ${ }^{17}$.

Así, el INPE ha suscrito un convenio con la Conferencia Episcopal Peruana el 7 de marzo de $2012^{18}$, prorrogado por cuatro años el 11 de marzo de $2016^{19}$. Con la Iglesia Cristiana Pentecostés del Perú - Movimiento Misionero Mundial firmó convenio el 17 de mayo de 2013, con vigencia hasta el 27 de mayo de $2021^{20}$. También tiene suscrito convenio con la Asociación las Asambleas de Dios del Perú, con vigencia por cuatro años desde el 24 de abril de $2018^{21}$.

\section{ASISTENCIA RELIGIOSA EN CENTROS HOSPITALARIOS}

\footnotetext{
${ }^{17}$ No debe confundirse estos convenios con los convenios de colaboración de los que se ocupa el artículo 15 de la LLR, propios del modelo de concertación y que no se limitan a la asistencia religiosa. Estos requieren del cumplimiento de las formalidades señaladas en ese artículo de la LLR. Aquellos (los suscritos por el INPE) corresponden más bien al modelo de libre acceso, donde el convenio busca básicamente establecer las condiciones del buen orden, régimen interior y las relaciones del centro penitenciario con los ministros religiosos, como lo relativo a la autorización para el libre acceso.

18 Disponible en: https://www.inpe.gob.pe/normatividad/convenios-1/convenio-region-lima/874-convenio2012-2016/file.html [consulta 2-10-2020].

19 Disponible en: https://www.inpe.gob.pe/normatividad/convenios-1/convenio-region-lima/875-convenio2016-2020/file.html[consulta 2-10-2020] .

20 Disponible en: https://www.inpe.gob.pe/normatividad/documentos/1973-convenio-adenda-mmminpe/file.html [consulta 2-10-2020].

${ }^{21}$ Disponible en: https://www.inpe.gob.pe/normatividad/convenios-1/convenio-region-lima/676-memo-mult131-2018-inpe,104-sec-gral-copia-fedateada-del-convenio-marco-de-cooperacion-interinstitucional-entre-laasoc/file.html [consulta 2-10-2020].
} 
Conforme al Acuerdo entre la Santa Sede y la República del Perú, el Estado garantiza que se preste asistencia religiosa a los católicos internados en los hospitales públicos. A tal efecto, los capellanes deberán contar con nombramiento eclesiástico, que será presentado a la autoridad competente (artículo XVIII).

Para las confesiones minoritarias que no tengan convenio de colaboración con el Estado, rigen las normas generales de la LLR, que reconoce el derecho a la asistencia religiosa en los centros hospitalarios públicos (artículo 3.c), la cual se imparte por los ministros de culto o agentes pastorales designados por las entidades religiosas, identificados con la credencial emitida por la entidad religiosa a la que pertenecen, que se renueva anualmente (artículo 6 del Reglamento LLR). Como dice López Alarcón, en tales cultos minoritarios «prima su derecho a que se facilite la asistencia espiritual, que es tan exigente en momentos tan íntimos como los que se arrostran ante el dolor y la proximidad de la muerte. De ahí que no quepa limitar la asistencia religiosa a miembros de confesiones inscritas o a las que tienen celebrados acuerdos de cooperación del Estado»22.

Precisamente por estas especiales circunstancias que atraviesan las personas internadas en establecimientos de salud (por tanto, en situación de especial sujeción), el Estado, en cumplimiento de su deber de preservar los derechos fundamentales, debe garantizar que estas puedan recibir, si lo solicitan, asistencia religiosa de su confesión por parte de sus respectivos ministros de culto.

Consideramos estrechamente vinculado con el derecho a la asistencia religiosa en centros hospitalarios, el derecho de toda persona a una sepultura digna por parte de sus familiares o seres queridos.

\footnotetext{
${ }^{22}$ LÓPEZ ALARCÓN, Mariano. «Asistencia religiosa» ..., cit., p. 323.
} 
El Tribunal Constitucional ha incluido ese derecho dentro de la libertad de culto, que a su vez se subsume en el derecho de libertad religiosa ${ }^{23}$. Esto explica que la LLR reconozca que la libertad religiosa comprende el derecho de «recibir sepultura de acuerdo con las tradiciones y ritos de la propia confesión religiosa, respetando en todo caso las normas vigentes sobre salud e higiene públicas» (artículo 3.h).

El Tribunal Constitucional ha llegado a decir que impedir el rito de una sepultura digna de los muertos por parte de sus familiares constituye una violación a la libertad religiosa (libertad de culto), que incluso linda con un trato cruel, inhumano o degradante, por el daño a la integridad moral de los familiares que ello significa ${ }^{24}$.

En esto coincide nuestro supremo intérprete de la Constitución con la jurisprudencia de la Corte Interamericana de Derechos Humanos, que considera una violación de derechos que se impida a las personas dar a sus familiares «una sepultura acorde con sus tradiciones, valores o creencias» ${ }^{25}$, y ha condenado al Estado que postergó o negó a los familiares de las víctimas la oportunidad de darles «una sepultura acorde con sus tradiciones, valores o creencias y, por lo tanto, intensificó sus sufrimientos» ${ }^{26}$.

\section{CONSIDERACIONES CONCLUSIVAS}

La Constitución Política del Perú reconoce el derecho de libertad religiosa en todas sus manifestaciones (artículo 2, inciso 3), entre las que se cuenta la práctica de la religión, que sustenta la asistencia religiosa.

\footnotetext{
${ }^{23}$ Cfr. STC 256-2003-HC/TC, fundamento 16.

${ }^{24}$ Cfr. STC 256-2003-HC/TC, fundamentos 18 a 20.

${ }^{25}$ Caso de las Masacres de Ituango Vs. Colombia, Sentencia de 1 de julio de 2006, párrafo 260.

${ }^{26}$ Caso de los «Niños de la Calle» (Villagrán Morales y otros) Vs. Guatemala, Sentencia de 19 de noviembre 1999, párrafo 173.
} 
Junto con ello la Constitución (artículo 50) consagra el principio de laicidad del Estado y, al mismo tiempo, el principio de colaboración entre este y las confesiones religiosas. Es en el marco de esta colaboración que encuentra fundamento la asistencia religiosa, que debe proveerse tanto a los fieles católicos como a los de otras confesiones, en aplicación del derecho-principio de igualdad religiosa (artículo 2, inciso 2, de la Constitución).

Y es que la asistencia religiosa está dirigida a las personas internadas en centros estatales en situaciones denominas de especial sujeción (centros penitenciarios, Fuerzas Armadas y Policiales, hospitales) y que, por tanto, ven disminuidas sus posibilidades de recibir asistencia religiosa. Se requiere, entonces, que el Estado -dentro del marco del principio constitucional de colaboración- proporcione los medios que permitan que tales internos puedan recibir dicha asistencia espiritual directamente de sus respectivas confesiones.

A partir de la revisión del modelo constitucional y de su desarrollo normativo (LLR y su Reglamento) y jurisprudencial, podemos decir que en el ordenamiento jurídico peruano coexisten dos modelos de asistencia religiosa: de concertación y de libre acceso. En el primero está el Acuerdo con la Iglesia católica de 1980 y los demás acuerdos que el Estado pueda suscribir con otras confesiones religiosas. El segundo modelo comprendería a aquellas confesiones que no cuentan con convenios de colaboración con el Estado, pero donde este tiene igualmente el deber de facilitar el ejercicio del derecho a la asistencia religiosa por respeto al principio-derecho de igualdad. 